\title{
Covid-19: UK advisory panel members are revealed after experts set up new group
}

\author{
Elisabeth Mahase
}

The BMJ

The UK government has disclosed some of the members of its Scientific Advisory Group for Emergencies (SAGE) after being criticised for a lack of transparency over its handling of the covid-19 pandemic and concerns over who was attending meetings.

A list of the SAGE membership has been published, ${ }^{1}$ with two names withheld because of a lack of consent over being named. Fifty members have been listed, including some that were already known, such as Neil Ferguson from Imperial College London, whose modelling study led to the government tightening restrictions. $^{2}$

Responding to the publication, the chair of the parliamentary Science and Technology Committee, Greg Clark, said, "This was something my committee called for in order to provide public reassurance that government decisions are informed by a broad and substantial body of expert advice."

However, others expressed concern over a lack of representation of certain specialties.

Amitava Banerjee, associate professor in clinical data science and honorary consultant cardiologist at University College London, said, "Given the rapidly changing nature of this epidemic and pandemic, perhaps further representation by frontline clinical academics, non-communicable disease clinical specialties, and global health experts may be beneficial in order to plan for the wider system response which has been and will be required."

The group's membership was made public after a new group, named the Independent SAGE, was set up by former chief scientific adviser David King. The group held a press conference and its first meeting on 4 May. ${ }^{3}$

The alternative group said its remit was to provide the government with evidence based policies to tackle covid-19. But it also had several questions it said the government needed to answer, such as whether the UK's policy was aimed at suppressing or managing covid-19, because these required two different strategies.

It also emphasised the importance of local ownership for testing and tracing infections and the need to ensure financial security for the most marginalised and ethnic minority groups. The group also said a new policy was needed at ports to prevent new cases of covid-19 entering the country and said that the potential of a vaccine to end the pandemic should not be overemphasised.

The group said that it would livestream its meetings to help keep the public better informed about the available emerging evidence and the full range of decisions the UK government could take to tackle the pandemic.

King, who is chairing the group, said, "Science is fundamentally a system based on peer review; when it comes to scientific advice of any kind, transparency is essential. The world has been humbled by covid-19, and yet as a scientific community we have been working for many years in expectation of a virus of this very kind.

"Surely now is the time for a new paradigm. This virus has shown borders are no defence to such threats. Our response moving forward must be proportionate in both scale of budget and collaboration."

\section{Some members of the Independent SAGE group}

Gabriel Leung, epidemiologist and epidemic control clinician, Hong Kong University

- Gabriel Scally, president of epidemiology and public health, Royal Society of Medicine

- Helen Ward, professor of public health, Imperial College London

- Allyson Pollock, professor of public health, University of Newcastle

- Anthony Costello, professor of global health, University College London (UCL)

- Karl Friston, computational modeller, UCL

- Susan Michie, behavioural psychologist, UCL

- Deenan Pillay, professor of virology, UCL, and former SAGE member

- Kamlesh Kunti, professor of primary care and diabetes, University of Leicester

- Christina Pagel, mathematician and professor of operational research, UCL

- Zubaida Haque, deputy director of race equality think tank Runnymede Trust

- Alison Pittard, dean, Faculty of Intensive Care Medicine

- Martin McKee, professor of European public health, London School of Hygiene and Tropical Medicine, and adviser to WHO

Government Office for Science. List of participants of SAGE and related sub-groups. 4 May 2020. https://www.gov.uk/government/publications/scientific-advisory-group-foremergencies-sage-coronavirus-covid-19-response-membership/list-of-participants-ofsage-and-related-sub-groups.

2 Mahase E. Covid-19: UK starts social distancing after new model points to 260000 potential deaths. BMJ 2020;368:m1089. 10.1136/bmj.m1089 32184205

3 Independent SAGE Live Stream. YouTube. 4 May 2020. https://www.youtube.com/watch? $v=z$ EwF34eel21\&list=UUqqwC56XTP8F9zeEUCOttPQ.

Published by the BMJ Publishing Group Limited. For permission to use (where not already granted under a licence) please go to http://group.bmj.com/group/rights-licensing/ permissions 
